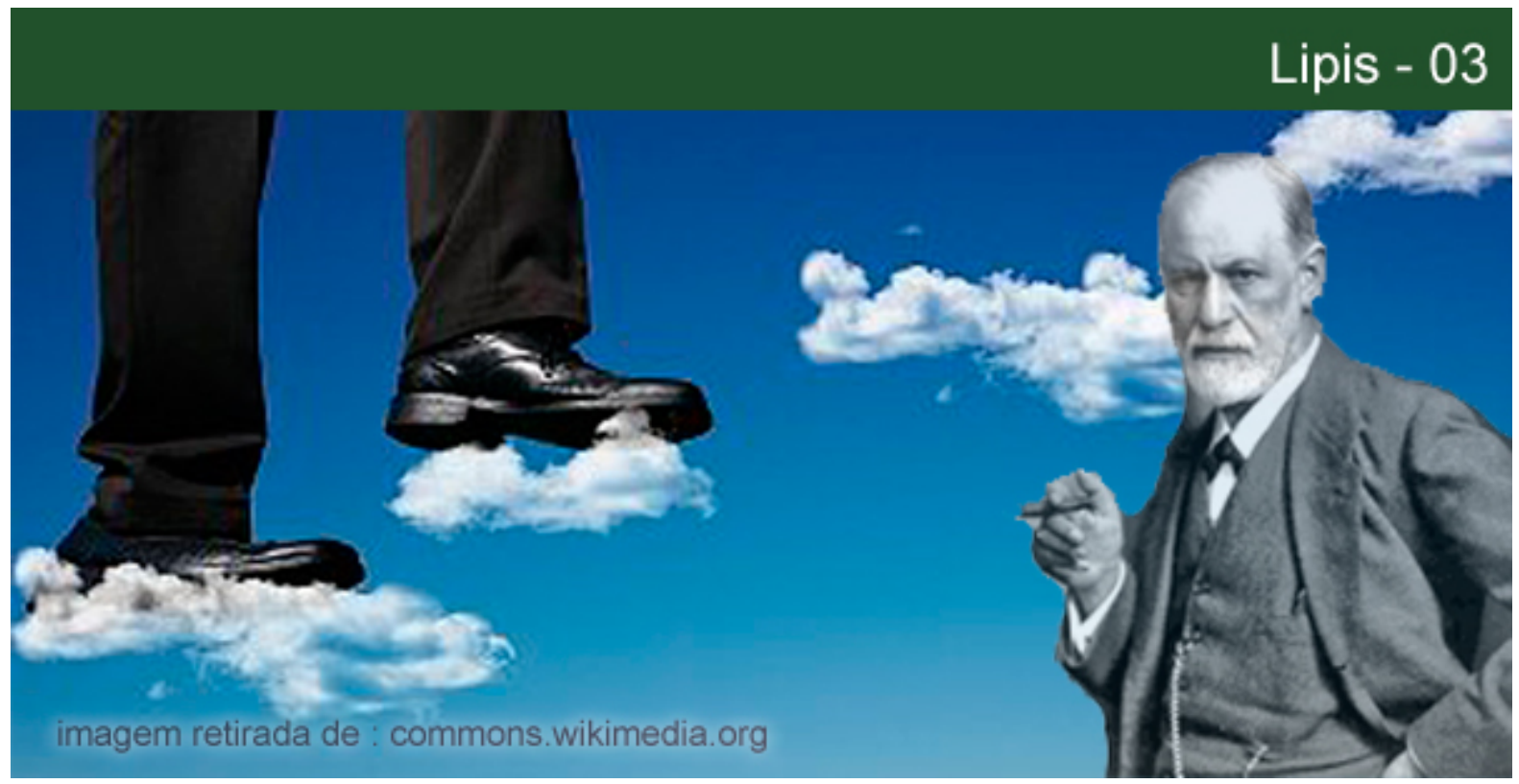

\title{
METÁFORAS DO SONHAR: A SUPERVISÃO CLÍNICA COMO ESPAÇO TRANSICIONAL.
}

\author{
Nadja Nara Barbosa Pinheiro \\ Professora Associada da Universidade Federal do Paraná (UFPR). Mestre e Doutora em Psicologia Clínica. \\ Pesquisadora do Laboratório de Psicanálise (DEPSI/UFPR) e do Laboratório Interdisciplinar de Pesquisa e \\ Intervenção Social (LIPIS-PUC/RJ).E-mail: nadjanbp@ufpr.br.
}

Resumo: A experiência profissional como docente do curso de graduação em Psicologia, em uma Universidade Federal, baseia as considerações propostas pela autora sobre a questão da supervisão clínica em estágios curriculares obrigatórios efetuados por alunos de quarto e quinto ano da graduação, no âmbito da clínica-escola da universidade. Respaldando-se na perspectiva psicanalítica, a autora toma como ponto de partida a ideia, apresentada por Freud, que o trabalho clínico deve seguir o modelo do processo onírico. Baseando-se na hipótese enunciada por Winnicott sobre a faculdade transicional dos sonhos, propõe a compreensão do espaço de supervisão como metáforas do sonhar, ou seja, como espaço transicional no interior do qual a instauração do jogo criativo permite a construção de realidades compartilhadas a partir dos elementos aí dispostos. Tais considerações sustentam a tese da autora de que, para que a prática de estágio curricular possa ter uma sustentação psicanalítica, faz-se necessário que o entrelaçamento, proposto por Freud, entre clínica e teoria, seja mantido derivando deste a noção de que o processo clínico não se resume ao momento das sessões estabelecidas entre alunos e pacientes, mas inclui o espaço de supervisão em sua transicionalidade.

Palavras-chave: Supervisão. Psicanálise. Universidade. Sonhos. Transicionalidade.

\section{DREAM'S METAPHOR: CLINICAL SUPERVISION AS A TRANSICIONAL SPACE}

Abstract: The professional experience as a teacher of undergraduate degree in Psychology, in a Federal University, base the considerations proposed by the author on the issue of clinical supervision in internships, performed by students of fourth and fifth graduation's year at the clinical-school of the university. Backing up on the psychoanalytic perspective, the author takes as its starting point, the idea put forward by Freud, that clinical work should follow the model of the dream process. Based on the hypothesis stated by Winnicott on the transitional function of dreams, proposes thr understanding of the space of supervision as a metaphors of dreams, that is, as a transitional space within which the establishment of creative play allows the construction of realities shared from the elements arranged therein. Such considerations support the thesis of the author that for the traineeship may have a psychoanalytic support, it is necessary that the entanglement proposed by Freud between practice and theory be maintained. Deriving from this, the notion that clinical process is not completed

\section{POLÊM!CA $\mid$ LABORE}

Polêmica - Revista Eletrônica da Uerj - Rua São Francisco Xavier, 524, $1^{\circ}$ andar bloco D, sl.1001 • Tels.: +55 21 2334-4088 / 4087 • http://www.e-publicacoes.uerj.br/index.php/polemica/index http://www.labore.uerj.br • laboreuerj@yahoo.com.br 
with the sessions established between students and patients, but includes the space of supervision in its transitionality.

Keywords: Supervision. Psychoanalysis. University. Dreams. Transitionalidade.

\section{Introdução}

Desde Freud, as relações entre psicanálise e universidade são objeto de questionamento e reflexão. Em um de seus textos, o autor se refere explicitamente sobre o ensino da psicanálise nas universidades e apresenta sua tese de que, se por um lado a psicanálise poderia prescindir da universidade, esta última muito se beneficiaria em ter em seus cursos disciplinas relativas aos conceitos psicanalíticos (FREUD,1919/1976a). Discussões à parte, fato é que, levando adiante o legado freudiano, por inúmeras razões históricas, no Brasil, o ensino da psicanálise nas universidades tem sido frequente nos cursos de graduação em psicologia. Nesses cursos, a psicanálise é apresentada como um dos sistemas teóricos, entre outros, que fornece subsídios para o entendimento da subjetividade e, em decorrência, para o exercício da prática clínica dos profissionais da psicologia. No entanto, embora tal inserção já esteja consolidada, ela não se faz isenta de dúvidas, questionamentos, impasses e discussões que podem ser efetuadas a partir de inúmeros e distintos eixos. No presente artigo, proponho uma discussão sobre uma questão específica referente à clínica psicanalítica desenvolvida no âmbito universitário como um dos requisitos parciais à obtenção do título de Psicólogo. Focalizei, aqui, o processo de supervisão efetuado ao longo dos estágios obrigatórios constante nos currículos de graduação em Psicologia, os quais possuem por objetivo a preparação dos alunos para o exercício profissional da prática clínica. Na universidade em que trabalho, especificamente, em tal modalidade de estágio, os alunos de quarto e quinto ano do curso de psicologia oferecem, entre outras atividades, atendimento psicoterapêutico individual à comunidade nas dependências da clínica-escola da própria universidade. A supervisão, obrigatória em termos curriculares, se processa uma vez por semana, em grupo de quatro alunos e um professor, para discutirem a condução dos atendimentos em andamento.

As considerações que apresento nesse artigo se baseiam na experiência que venho desenvolvendo no âmbito da graduação em Psicologia como supervisora de estágio em clínica já há alguns anos. Atividade que, no meu entender, se interliga, necessariamente, às funções de docente e de pesquisadora. Nessas, incluo-me entre os professores responsáveis pela apresentação das disciplinas curriculares que versam sobre os fundamentos conceituais da

\section{POLÊM!CA $\mid$ LABORẸ}

Polêmica - Revista Eletrônica da Uerj - Rua São Francisco Xavier, 524, $1^{\circ}$ andar bloco D, sl.1001 • Tels.: +55 21 2334-4088/4087 • http://www.e-publicacoes.uerj.br/index.php/polemica/index http://www.labore.uerj.br • laboreuerj@yahoo.com.br 
teoria psicanalítica, assim como orientação de trabalhos de conclusão de curso e de dissertações, coordenação de grupos de estudos e pesquisa em psicanálise. Compondo com dois outros professores o Laboratório de Psicanálise, partimos do princípio que levar adiante o legado freudiano no âmbito universitário requer a organização de atividades que interliguem pesquisa e clínica, de tal forma que o estudo teórico se entrelace ao pensamento clínico. Nesse contexto, os estágios supervisionados se apresentam como uma oportunidade única, na universidade, para que tal estratégia de pensamento possa ser sustentada e vivenciada pelos professores, mas, sobretudo, pelos próprios alunos. Tal especificidade inclui a necessidade de tomarmos a clínica do estágio e, em consequência, a supervisão a ele vinculada, como foco de nosso interesse e de nossa constante tematização e questionamento. Ao longo dos anos, viemos nos dedicando, sobretudo, a indagações constantes sobre as possibilidades de existência de uma clínica psicanalítica no âmbito universitário. E, embora convicta de que a condução das supervisões pela via da psicanálise não garanta que a clínica do estágio que aí se estabelece se configure como um processo analítico, acredito que, igualmente, o fato de estarmos inseridos no âmbito universitário, não define sua impossibilidade. Sendo a possibilidade de que algo da psicanálise possa operar na clínica do estágio, reservada como horizonte, aquilo que me mantém no desejo de ocupar o lugar de supervisora clínica e, concomitantemente, o de docente em uma universidade.

As preocupações acima relatadas subsidiaram o desenvolvimento de uma pesquisa cientifica na qual, partindo do posicionamento freudiano de que, na psicanálise, tratamento e investigação coincidem, nos indagamos, sobretudo, sobre as condições de possibilidade da clínica psicanalítica operar no âmbito da universidade. Nesta pesquisa, uma das primeiras demarcações que nos pareceu importante diz respeito à delimitação do lugar que o saber ocupa na universidade e na psicanálise. Sabemos que durante todo o curso de graduação os alunos tomam a ciência psicológica como um saber a ser ensinado, aprendido e aplicado à clínica. No entanto, ao serem apresentados à clínica da psicanálise, uma das primeiras “aprendizagens” efetuada diz respeito ao fato que, na psicanálise, o saber não antecede à clínica, mas se constrói no seio de seu próprio exercício. De forma condizente ao modus operandis universitário, aquele a quem os alunos se endereçam aos seus supervisores clínicos, em busca de um maior saber conceitual desejando que o supervisor possa antecipar, tecnicamente, suas intervenções clínicas. Porém, seguindo o pensamento psicanalítico, o supervisor se furta em ocupar esse lugar e, em lugar do saber, oferece sua escuta.

\section{POLÊM!CA | LABORẸ}

Polêmica - Revista Eletrônica da Uerj - Rua São Francisco Xavier, 524, $1^{\circ}$ andar bloco D, sl.1001 • Tels.: +55 21 2334-4088/4087 • http://www.e-publicacoes.uerj.br/index.php/polemica/index http://www.labore.uerj.br • laboreuerj@yahoo.com.br 
Desde essa proposição sobre o lugar do saber na psicanálise, propusemos em nossa pesquisa, a necessidade de duas operações:

1- Que, ao longo dos estágios clínicos, alunos e supervisores se desloquem do lugar de estudantes e supervisores/docentes para o de 'aprendizes à análise’. Precisando que utilizamos o termo ‘aprendizes’ para situarmos que, na clínica da psicanálise, não há lugar especificamente para um professor e para um aluno na medida em que seu objeto de conhecimento, o inconsciente, não se oferece ao campo objetivo do ensino e da aprendizagem. Mas, é apreensível pela via da transmissão, no interior da própria clínica, no encontro de cada analisando com seu próprio inconsciente. Sendo este talvez um dos maiores impasses a ser considerado na clínica desenvolvida no seio da universidade, posto que nesta, o ‘aprendiz’ chega à clínica pela via do aluno e não pela via do analisante (DARRIBA \& PINHEIRO, 2010).

2- $\quad$ Que não há um saber técnico que pode ser construído fora da própria clínica, que a anteceda e que possa ser nela aplicado. Mas, no movimento que se abre pela construção do campo transferencial, pode o analista operar seu ofício na direção de oferecer possibilidades para que ocorra a emergência de conteúdos do inconsciente.

No interior dessas considerações que insiro a minha proposta de promover, na presente oportunidade, uma reflexão sobre o trabalho de supervisão clínica desenvolvido no âmbito de uma clínica-escola e referente ao estágio obrigatório curricular para a obtenção do grau de Psicólogo. Atividade que, na clínica do estágio, constitui uma entre as inúmeras disciplinas curriculares, na qual é exigida a frequência e a aferição de uma nota final a cada aluno. Se tais elementos são indicativos de um afastamento do campo psicanalítico, em contrapartida, sugiro que o afastamento não constitui impedimento. Para tal, minha proposição é a de que não devemos entender que as sessões que os alunos desenvolvem com seus pacientes e as respectivas supervisões constituam dois processos distintos, mas como momentos constitutivos de um mesmo processo que se desenrola ao longo de uma temporalidade e espacialidade singulares. Para sustentar minha argumentação, sugiro tomar a noção winnicottiana de transicionalidade como eixo norteador de minhas proposições. Pela via da transicionalidade, proponho conceber a supervisão como espaço transicional no qual os elementos em seu âmbito alocados recebem novas configurações a partir do trabalho/jogo em

\section{POLÊM!CA | LABORẸ}

Polêmica - Revista Eletrônica da Uerj - Rua São Francisco Xavier, 524, $1^{\circ}$ andar bloco D, sl.1001 • Tels.: +55 21 2334-4088/4087 • http://www.e-publicacoes.uerj.br/index.php/polemica/index http://www.labore.uerj.br • laboreuerj@yahoo.com.br 
que todos tomam parte: alunos e supervisor, como 'aprendizes à análise’. Para tal, parto de algumas proposições freudianas sobre o sonhar como modelo clínico. No processo onírico, destaco a capacidade transicional dos mesmos, para, por fim, indicar a supervisão como metáfora do sonhar e fazer dela um dos elementos fundamentais para a transmissão da clínica psicanalítica, também na universidade.

\section{Freud: sonhos, transferência e clínica.}

Tomarei como referência o texto freudiano 'A Interpretação dos Sonhos' (FREUD, 1900/1976b). Nele, destaco um elemento muitas vezes negligenciado quando pensamos no trabalho onírico: o fato de Freud frisar a função fundamental dos restos diurnos. O autor nos assevera que o trabalho onírico depende, por um lado, do desejo inconsciente que movimenta as representações e, por outro, das experiências diurnas que movimentaram o sonhador em seu cotidiano. Sobre essas vivências, sobre os afetos aí suscitados, sobre os conflitos aí tencionados, que os sonhos podem se constituir na medida em que 'despertam' os desejos inconscientes. Ou seja, em meu entendimento, o autor já está destacando, com essa afirmação, a existência de uma ponte que interliga, de forma primorosa, as realidades interna e externa.

Em seu argumento, o trabalho onírico depende que o sonhador se desligue dos estímulos ambientais. Que o ego se desfaça de suas proteções e recupere um modo peculiar de operar: narcisicamente absorto em si-mesmo, paradoxalmente, totalmente integre ao ambiente. Esse posicionamento permite que a energia psíquica retroaja, isto é, tome um caminho regressivo, contrário ao sentido habitual, e reinvista inúmeras representações. O modo regressivo de distribuir energia se faz em três planos: tópico, ou seja, do Consciente para o ICS; temporal, das vivências atuais para as mais remotas na infância; modal, isto é, do processo secundário para o primário, reinvestindo de forma 'alucinatória' as vivências primitivas.

Temos aqui, então, o que há de muito especial nos sonhos: um modo particular de circulação da energia psíquica que desfaz a dicotomia entre realidade externa e interna, entre passado e presente, entre alucinação e realização de desejos. Um trabalho que reativa os modos primitivos de funcionamento psíquico e que permite, assim, uma transição entre variados planos, modos, funções e organizações, produzindo novas configurações, transformações, construções.

\section{POLÊM!CA | LABORË}


Freud destaca, então, que é sobre esse funcionamento diferenciado que o trabalho onírico se manifesta, inserindo nas representações cotidianas, nos restos diurnos, uma gama infinita de sobreposições. Restos diurnos que se apresentam como suporte para a realização de desejos infantis, no momento atual de sua concretização. Ou seja, embora a dicotomia mundo interno/mundo externo seja transfigurada, ela permanece atuante na medida em que o sono é precedido e seguido pela vida de vigília.

Sustentado nessas premissas, em Dora, Freud (1904[1901]/1976c) nos faz uma indicação preciosa: esse modelo onírico é o modelo a ser tomado na clínica. Ou seja, é mister observar que o campo transferencial segue o modelo onírico. Ela, a transferência, também toma as experiências atuais e cotidianas como suporte para a emergência das vivências infantis e primitivas. Tal como o sonho, a transferência permite um modo de operar via condensação, fazendo do analista suporte para sobreposições de imagos infantis. Ou operando via deslocamento, o paciente vivencia, na análise, o que já se vivenciou outrora, unindo e separando, passado e presente, processo primário e secundário, alucinação e realização de desejos. Não à toa, Freud (1912/1976d) nos assevera que a transferência é uma área intermediária entre a saúde e a doença, entre o presente e o passado, entre a realidade interna e a externa, playground sobre o qual o trabalho clínico transcorre.

Assim como nos sonhos, portanto, a transferência se apresenta como uma área de 'trânsito' para diferentes conteúdos, representações, desejos, realidades. Permitindo constantes reorganizações e funcionalidades. Tal como os sonhos, a transferência é campo de transformação, de produção, de construção, de criação.

Minha proposta é que podemos transpor esse modelo, que perpassa sonhos e transferência, para a ideia de supervisão clínica como pura transição, como metáfora do sonhar que transfigura o que está sendo trabalhado ao longo das sessões clínicas transcorridas entre estagiários e pacientes. Para melhor esclarecer, sigamos com Winnicott na tentativa de melhor elucidarmos seu pensar transicional e passarmos posteriormente a algumas considerações a respeito das supervisões ocorridas em um ambiente universitário.

\section{Winnicott: transicionalidade, subjetividade e clínica}

Em meu entender, podemos significar transicionalidade, no pensamento de Winnicott, como essa capacidade explicitada pelos sonhos de circulação que permite o transitar entre diferentes modos de organizar o material psíquico e afetivo. Isto é, a circulação se estabelece

\section{POLÊM!CA $\mid$ LABORẸ}

Polêmica - Revista Eletrônica da Uerj - Rua São Francisco Xavier, 524, $1^{\circ}$ andar bloco D, sl.1001 • Tels.: +55 21 2334-4088/4087 • http://www.e-publicacoes.uerj.br/index.php/polemica/index http://www.labore.uerj.br • laboreuerj@yahoo.com.br 
em termos econômico, dinâmico e tópico, indicando que as dimensões sobre as quais se processa são distintas, embora relacionadas. Em termos vivenciais, recupera-se, no sonhar, modos primitivos de organizar material psíquico. Como informa Freud (1900/1976b), decompõe-se pensamento em imagens, reatualizando cotidianamente o que há de mais primitivo em termos subjetivos.

Mas, o importante aqui é frisar que nessa circulação, uma vez que o despertar seja efetivado, o resultado alcançado por meio desse processo complexo, são novas organizações do material psíquico, tanto em termos representacionais quanto afetivos, e não a desorganização psíquica como poderia se esperar. Isto é, quando Freud (1917/1976e) assinala que o sonhador se desfaz de suas proteções e se entrega ao sono, o resultado desse mergulho ao primitivo proporcionado pelo sonhar, ao acordarmos no dia seguinte, é a aquisição de novas organizações as quais permitem que as relações entre as instâncias psíquicas encontrem um certo apaziguamento de suas tensões. Como nos informa Freud (1900/1976b), os sonhos, ao permitirem que desejos inconscientes sejam realizados, de uma forma que não perturbe o consciente em demasiado, exercem uma função organizadora privilegiada e fundamental para o viver.

No meu entender, é essa função primordial de produzir novos rearranjos subjetivos o que é destacado por Winnicott (1971/1983a) ao tratar dos fenômenos transicionais. Ou seja, fenômenos que permitem que essas 'passagens' sejam efetuadas e cujos resultados são a criação de novas significações, sentidos e contornos para experiências e vivências primitivas que permanecem, ao longo dos anos, fontes de tensão e inquietação subjetiva.

Para melhor entendermos o que significa transicionalidade para Winnicott, devemos perceber que o ponto básico de seu pensamento se pauta em sua tentativa de compreender como se processa a trajetória pessoal de um ser humano desde o momento em que se encontra em um estado subjetivo indiferenciado em relação a outro ser humano que dele cuida ao nascer, até um estado subjetivo em que é possível perceber a distinção entre um eu e um outro. Trajetória esta que deve ser marcada pela manutenção de uma sensação de continuidade-de-existência, a despeito das 'descontinuidades' vivenciadas ao longo do inconstante processo de viver. Winnicott (1945/2000a) destaca alguns elementos importantes nessa trajetória, assinalando a existência de diversos planos existenciais que nela se conectam. A princípio, salienta o autor, somente há um bebê em potencial, pois esse só existe no âmbito do desejo dos pais. Ao nascer, acrescenta Winnicott (1945/2000a), há um plano das

\section{POLÊM!CA $\mid$ LABORẸ}

Polêmica - Revista Eletrônica da Uerj - Rua São Francisco Xavier, 524, $1^{\circ}$ andar bloco D, sl.1001 • Tels.: +55 21 2334-4088/4087 • http://www.e-publicacoes.uerj.br/index.php/polemica/index http://www.labore.uerj.br • laboreuerj@yahoo.com.br 
necessidades somáticas a serem satisfeitas para que a vida orgânica seja mantida. Em contrapartida, há um plano do Ambiente/mãe que atende a essas necessidades, recorrentemente, de forma a manter não apenas a vida orgânica, mas igualmente a vida psíquica que, inicialmente, são indistintas, mas que gradualmente vão se diferenciando e se intercomunicando. O importante, nos informa o autor, é que percebamos que o encontro entre esses distintos planos do viver (orgânico, psíquico e ambiental) permite a construção de uma área de experimentação, de sobreposição entre si, no interior da qual a trajetória humana ganha corpo. Assim, o autor destaca que essa trajetória se principia em um momento de completa e absoluta dependência do bebê a um ambiente que satisfaça suas necessidades orgânicas/psíquicas. Passa por um gradativo processo de diminuição dessa dependência, possibilitado pelas sucessivas falhas desse Ambiente em atender a essas mesmas necessidades. E nesse espaço, na brecha aberta por essas falhas, a dependência ao Ambiente vai se tornando relativa, permitindo um lento e inacabado rumo à independência.

Importa salientar que, nessa concepção, a princípio, por encontrar-se indiferenciado em relação ao Ambiente/mãe, este último não se constitui como um objeto para o bebê. Sendo, portanto, a criação de objetos subjetivos a primeira operação psíquica a ser efetuada no processo de desenvolvimento emocional. Aqui Winnicott (1947/2000b) lança mão do paradoxo para indicar que essa construção depende por um lado do potencial à criatividade inato de todo ser humano, mas que só pode se realizar face às provisões ofertadas pelo Ambiente/mãe. Isto é, se o mundo é criado pelo bebê, tal operação se processa a partir dos esforços conjuntos entre o potencial criativo herdado e os elementos apresentados pelo ambiente. Portanto, apresentação de objetos e criação dos mesmos se implicam, embora não se equivalham. Objeto criado e objeto apresentado não são o mesmo, mas a existência de um é exigência para a existência do outro. É nesse sentido que para Winnicott (1971/1983a) fazse necessário concebermos a existência de uma área específica entre apresentação e criação de objetos no interior da qual essas operações possam ocorrer. Área esta que permite que os objetos apresentados e objetos subjetivamente criados se interliguem e, simultaneamente, se mantenham diferenciados. Ou seja, os objetos, no interior dessa área de manipulação, assumem diferentes dimensões, de subjetivamente concebidos a objetivamente percebidos. Entre ambos, alguns objetos permitem a transição entre esses, sendo denominados por Winnicott (1953/1983b) como objetos transicionais. Nos parece interessante salientar que, no pensamento winnicottiano, essa área de experimentação constitui um espaço que indica que a

\section{POLÊM!CA $\mid$ LABORE}

Polêmica - Revista Eletrônica da Uerj - Rua São Francisco Xavier, 524, $1^{\circ}$ andar bloco D, sl.1001 • Tels.: +55 21 2334-4088 / 4087 • http://www.e-publicacoes.uerj.br/index.php/polemica/index http://www.labore.uerj.br • laboreuerj@yahoo.com.br 
potencialidade à criatividade pode operar tendo como suporte a presença do ambiente. Área de manipulação e experimentação para a qual concorrem singularidade e alteridade. Área que delimita não apenas o interno e o externo, mas o que há de compartilhado entre os semelhantes, na qual mundos são criados, regras estabelecidas, contornos adquiridos, sentidos e significados são alcançados. Para Winnicott (1971/1983a), é nessa área que se vive a transformação dos mundos interno e externo, o encontro com o que há de mais pessoal, assim como com a mais radical alteridade. Área de transformação no interior da qual as transições entre estados subjetivos, modos de organização psíquica e formas de relacionamento com os objetos podem ocorrer. Área, portanto, relativa à transicionalidade na qual a trajetória subjetiva se processa e se conecta com a sociabilidade.

Por esses motivos, em minha opinião, ao postular sua elaboração de objeto transicional, Winnicott (1971/1983a) não apenas nos apresentou uma teoria sobre as relações objetais, mas, principalmente, nos ofereceu um modo específico de pensarmos a construção da subjetividade. Posto que suas considerações demarcam, sobretudo, a trajetória do viver humano a partir da criação de um espaço paradoxal no qual a potencialidade da criatividade pode operar tendo como suporte a presença do ambiente. Área de manipulação e experimentação para a qual concorrem singularidade e alteridade. Área que delimita não apenas o interno e o externo, mas o que há de compartilhado entre o homem e seus semelhantes.

Partindo dessas noções básicas, acredito que podemos conceber a transicionalidade, no seio do pensamento de Winnicott, como uma via de mão dupla que permite o trânsito entre: a) estados subjetivos diferenciados (da dependência absoluta a uma relativa independência); b) modos distintos de organização do material psíquico (do princípio do prazer ao princípio da realidade); c) diferentes modos de relacionamento com os objetos (de uma fusão inicial com o objeto, às possibilidades de estabelecer relações objetais com estes).

Tomando esses elementos como característicos da transicionalidade, podemos relacioná-los com os processos oníricos tal como os descrevemos acima, fazendo valer sua função transicional, na medida em que os sonhos permitem não apenas as operações de passagem e transição, mas, também, contínuas reorganizações do material psíquico e afetivo. Dessa forma, em conclusão, se Freud nos indica que a clínica psicanalítica se funda no modelo onírico, podemos intuir que a clínica se funda, portanto, na própria transicionalidade. Um espaço que se institui entre pacientes e analistas, no qual opera a experimentação e a

\section{POLÊM!CA $\mid$ LABORẸ}

Polêmica - Revista Eletrônica da Uerj - Rua São Francisco Xavier, 524, $1^{\circ}$ andar bloco D, sl.1001 • Tels.: +55 21 2334-4088/4087 • http://www.e-publicacoes.uerj.br/index.php/polemica/index http://www.labore.uerj.br • laboreuerj@yahoo.com.br 
movimentação. Ou seja, se há clínica, ela é fundamentalmente transicional na medida em que sua operacionalidade se refere à possibilidade de reinstaurar a potencialidade da criatividade face à alteridade (WINNICOTT, 1969/1983c).

A minha intenção agora é a de sustentar que a mesma estratégia de pensamento pode ser adotada em relação às supervisões clínicas ocorridas em um espaço universitário, na medida em que a entendamos como um espaço, fundamentalmente, onírico e transicional.

\section{Apontamentos sobre as supervisões na clínica da universidade}

Na universidade em que trabalho, nos estágios obrigatórios profissionalizantes, nos quais os alunos desenvolvem atendimento clínico à comunidade, as supervisões são efetivadas por um professor, em grupo de quatro alunos, para duas horas de supervisão semanal. Geralmente, ao longo das supervisões, os alunos relatam as sessões transcorridas com seus pacientes. Notadamente, há uma primeira tentativa efetuada pelos alunos de tonarem as supervisões como espaço de instrução técnica no qual o professor/supervisor pudesse explicar, didaticamente, o que ocorre nas sessões e indicasse o que os alunos deveriam executar. Nesse sentido, percebo a ocorrência de uma flagrante tentativa, efetuada pelos alunos, de produzir uma análise psicanalítica do discurso de seus pacientes. Ou seja, como se alunos e supervisor, ao deterem o conhecimento conceitual sobre os processos psíquicos, pudessem transcrever o discurso dos pacientes para uma linguagem psicanalítica, detectando no discurso destes, os processos descritos pelos conceitos. Percebo, também, que ao fazerem tal movimentação, afastam-se dessa forma, da possibilidade de permitir a emergência do material Inconsciente de seus pacientes. A qual poderia advir, quer seja pelos lapsos do discurso, quer seja pelas manifestações de movimentos transferenciais. Ou seja, afastando-se da possibilidade de percepção, que é justamente nas bordas do que não é dito que o objeto principal de seu trabalho, o Inconsciente, pode se manifestar.

Importa salientar que tal movimentação me parece ir ao encontro da própria organização subjetiva. Sabemos desde Freud que o processo de recalcamento possui sua função organizadora e defensiva para o Ego, na medida em que tornar Inconsciente desejos proibidos apazigua certas tensões. Assim, se pelo lado dos pacientes o material inconsciente se refere ao que é proibido e, portanto, recalcado, dele os pacientes nada querem saber. Por seu turno, os estagiários, ao disponibilizarem sua escuta ao Inconsciente de seus pacientes, também se deparam com conteúdos proibidos e recalcados de si mesmos na medida em que a

\section{POLÊM!CA $\mid$ LABORE}

Polêmica - Revista Eletrônica da Uerj - Rua São Francisco Xavier, 524, $1^{\circ}$ andar bloco D, sl.1001 • Tels.: +55 21 2334-4088 / 4087 • http://www.e-publicacoes.uerj.br/index.php/polemica/index http://www.labore.uerj.br • laboreuerj@yahoo.com.br 
Lei organizadora do recalque opera em todos. Ou seja, sobre esse material, os estagiários, assim como os pacientes, desejam nada saber. Me parece fácil perceber, portanto, que a estratégia frequentemente efetuada pelos estagiários, de trazer às supervisões um relato exaustivo do discurso produzido por seus pacientes em cada sessão, representa a dificuldade de todos nós em nos abrirmos à emergência do Inconsciente. No entanto, somente no momento em que, ao longo das supervisões, essa estratégia pode ser desconstruída, desmontada, desfeita, abre-se a brecha para a construção de um outro tipo de saber: aquele que se endereça ao saber sobre o Inconsciente, se tornando, assim, transformador.

Em termos de supervisão, proponho que nesse processo de desconstrução, o modelo onírico, descrito por Freud, se mostra precioso. Tomando o sonho como modelo, nas supervisões a linearidade temporal pode ser rompida. Palavras, movimentos, atos, afetos descritos pelos estagiários relativos a diferentes sessões de seus pacientes, podem ser reordenados e ressignificados. Afetos e sensações desconexos ganham novos contornos, atos desprovidos de racionalidade são percebidos e flexionados, sem que a cronologia temporal seja imperativa. Nos encontros de supervisão, portanto, estagiários e supervisores se remetem a outro espaço temporal, se deparam com manifestações e produções de seus próprios inconscientes, naquilo que estes permitem a escuta de certos indícios tomados como operados clínicos. Nelas, a partir dos elementos aí dispostos, desfaz-se os contornos singulares de cada participante e todos produzem considerações que se somam, se misturam, se multiplicam e indicam um produto final único e compartilhado que reverbera sobre cada fazer clínico singular. No meu entendimento, esse produto obtido no campo da supervisão não se coloca à parte das sessões, mas delas fazem parte, no sentido que o estagiário, ao retomar com seus pacientes singulares o trabalho clínico, o fazem a partir de um lugar no qual a transformação subjetiva (e, portanto, afetiva e inconsciente) tomou corpo, forneceu sustentação e produziu transformação. É nesse sentido, me parece, que a transicionalidade sustenta o exercício das supervisões, na medida em que entrelaça mundos internos e compartilhados, produzindo constantes e incessantes movimentos transformadores. Um trabalho que se apresenta sempre difícil na medida em que exige que tanto supervisores quanto estagiários afrouxem suas resistências e defesas e se abram à emergência do inesperado e do não antecipável.

Um trabalho de certa forma inusitado para os estagiários, na medida em que ruma no sentido contrário das propostas de ensino universitário. Pois se a universidade se pauta na construção de um saber cumulativo que garanta aos profissionais a aplicação técnica desse

\section{POLÊM!CA $\mid$ LABORẸ}

Polêmica - Revista Eletrônica da Uerj - Rua São Francisco Xavier, 524, $1^{\circ}$ andar bloco D, sl.1001 • Tels.: +55 21 2334-4088/4087 • http://www.e-publicacoes.uerj.br/index.php/polemica/index http://www.labore.uerj.br • laboreuerj@yahoo.com.br 
conhecimento em seus campos de trabalho, a clínica psicanalítica indica que diante do saber do Inconsciente não há técnica aplicável e nem conhecimento que o antecipe. Se há um saber sobre o inconsciente, esse saber é construído no interior da própria clínica. Ou seja, minha proposta é que assim como Freud indicou que, na psicanálise, não se deve tomar teoria e clínica como produções independentes, mas que se implicam no exercício de suas práxis, podemos incluir nesse conjunto o exercício da supervisão, compreendendo-a como metáfora do sonhar, transicional por excelência. Seguindo esse dispositivo, acredito que possamos avançar diante de alguns obstáculos importantes que se impõem à clínica do estágio nas universidades. Principalmente no que diz respeito à obrigatoriedade, à fragmentação, à segmentação entre teoria e clínica, entre saber e práxis, característicos do ensino universitário, permitindo que algo do saber psicanalítico possa ser transmitido. Claro está que nem sempre isso é possível, mas o fato de que o vejo ocorrer em alguns casos e em alguns momentos, me movimenta no sentido de ir adiante.

\section{Referências}

FREUD, S. A Interpretação de Sonhos. Obras Completas, ESB, v. V. Rio de Janeiro: Imago Editora, 1976b. (Trabalho original publicado em 1900).

. Fragmentos da análise de um caso de histeria. Obras Completas, ESB, v. VII. Rio de Janeiro: Imago Editora, 1976c. (Trabalho original publicado em 1904).

A dinâmica da transferência. Obras Completas, ESB, v. XII. Rio de Janeiro: Imago Editora, 1976 d. (Trabalho original publicado em 1912).

Suplemento metapsicológico à teoria dos sonhos. Obras Completas, ESB, v. XIV. Rio de Janeiro: Imago Editora, 1976e. (Trabalho original publicado em 1917).

. Sobre o ensino da psicanálise nas universidades. Obras Completas, ESB, v. XVII. Rio de Janeiro: Imago Editora, 1976a. (Trabalho original publicado em 1919).

DARRIBA, V. \& PINHEIRO, N. A clínica psicanalítica na universidade: reflexões a partir do trabalho de supervisão. Psicologia Clínica, v. 22, pp.45-55, 2010.

WINNICOTT, D. W. Desenvolvimento Emocional Primitivo. Textos selecionados: da Pediatria à Psicanálise. Rio de Janeiro: Francisco Alves Editora, 2000a. (Trabalho original publicado em 1945).

O ódio na contratransferência. Textos Selecionados: da pediatria à psicanálise. Rio de Janeiro: Francisco Alves Editora, 2000b. (Trabalho original publicado em 1947).

Objetos Transicionais e Fenômenos Transicionais. O Brincar e a Realidade. Rio de Janeiro: Imago Editora, 1983b. (Trabalho original publicado em 1953).

O Brincar: uma exposição teórica. O Brincar e a Realidade. Rio de Janeiro: Imago Editora, 1983a. (Trabalho original publicado em 1971).

\section{POLÊM!CA | LABORË}

Polêmica - Revista Eletrônica da Uerj - Rua São Francisco Xavier, 524, $1^{\circ}$ andar bloco D, sl.1001 • Tels.: +55 21 2334-4088/4087 • http://www.e-publicacoes.uerj.br/index.php/polemica/index http://www.labore.uerj.br • laboreuerj@yahoo.com.br 
O uso de um objeto e relacionamento através de identificação. O brincar e a Realidade. Rio de Janeiro: Imago Editora, 1983c. (Trabalho original publicado em 1969).

Recebido em: 14/02/2015.

Aceito em: 21/03/2016.

\section{POLÊM!CA $\mid$ LABORË}

Polêmica - Revista Eletrônica da Uerj - Rua São Francisco Xavier, 524, $1^{\circ}$ andar bloco D, sl.1001 • Tels.: +55 21 2334-4088/4087 • http://www.e-publicacoes.uerj.br/index.php/polemica/index http://www.labore.uerj.br • laboreuerj@yahoo.com.br 